Téoros

Revue de recherche en tourisme

\title{
Capitale nationale, culture régionale et tourisme
}

\section{Pierre Dubé}

Volume 7, numéro 1, mars 1988

Cultures régionales et tourisme

URI : https://id.erudit.org/iderudit/1080424ar

DOI : https://doi.org/10.7202/1080424ar

Aller au sommaire du numéro

Éditeur(s)

Université du Québec à Montréal

ISSN

0712-8657 (imprimé)

1923-2705 (numérique)

Découvrir la revue

Citer cet article

Dubé, P. (1988). Capitale nationale, culture régionale et tourisme. Téoros, 7(1),

9-10. https://doi.org/10.7202/1080424ar d'utilisation que vous pouvez consulter en ligne.

https://apropos.erudit.org/fr/usagers/politique-dutilisation/ 


\section{Capitale nationale, culture régionale et tourisme}

Les questions soulevées par les organisateurs du Colloque Téoros 1987 sont intéressantes à plus d'un point de vue, surtout lorsqu' on les analyse à travers une entité géographique et administrative forte, soit la région de la Capitale nationale ${ }^{(1)}$.

Comment concilier la culture régonale et le tourisme dans cette entité qui se veut le reflet du pays et où s'affrontent diverses cultures. notamment la culture anglo-saxonne, la culture francophone québécoise et francoontarienne et les diverses cultures ethniques?

Cet exposé est basé avant tout sur des faits et des observations. J'ai tenté de répondre aux questions des organisateurs d'abord dans. la perspective de la Capitale nationale et par le biais de l'Outaouais québécois, dont jaai tiré plusicurs exemples pertinents. La problématique du tourisme dans l'Outaouais est. fascinante. Cette région frontaliềre est confrontbe a une force externe qui exerce une attractivité énorme et qui structure dans une large mesure l'activitế touristique régionale.

\section{Une capitale verte... mais froide}

Ceux qui ont visité Ottawa, il y a dix ans et qui y reviennent constatent d'enormes changements. Sur le plan physique, bien sûr, car la récession économique n'a que peu touché cette ville dont l'économie est basée avant tout sur la fonction publique, mais egalement sur le plan social et culturel.

Dans de récents sondages à travers le pays, les répondants ont mentionné qu'Ottawa était intéressante sur le plan touristique en raison de son titre de Capitale, de son image de verdure, de siège du gouvernement, de dépositaire de certains musées... Ottawa demeure une belle ville grâce à ses parcs, son architecture, son prestige; mais ils ont aussi mentionné que la Capitale avait un caractère artificiel, une ville froide et sans âme, un endroit ennuyant où tout ferme tôt.

En fait, ce titre de Capitale comporte aussi des dangers, car on oublie trop souvent qu'elle est d'abord une ville avec ses beaџtés et ses laideurs. Pour le touriste, ce n'est pas vraiment un endroit de destination, mais une étape sur un circuit qui comprend surtout Montréal et Toronto. Car à moins d'y avoir des amis ou de la parenté, on a plutôt tendance à ne pas faire le détour. Surtout que de Montréal ou de Toronto, la côte américaine est de loin bien plus attirante.

\section{David et Goliath}

En traversant la rivière des Outaouais, le touriste reçoit une image plus floue. A Hull et dans le reste de l'Outaouais, on ne peut vraiment dissocier le développement du tourisme de celui d'Ottawa. La compétition entre David et Goliath est visible (bien que dans I'histoire David ait gagné). Hull a actuellement à offrir aux touristes ses bars et discothèques et bientôt un superbe musée des Civilisations. Le caractère et l'ambiance y sont totalement différents d'Ottawa. Quant au reste de la région, il y a le pare de la Gatineau, les centres de ski et de villégiature, les pourvoiries, bref la grande nature.

L'Outaouais possède un enorme potentiel touristique complémentaire à celui d'Ottawa. La position géographique de la région est privilégiée, son paysage agricole et forestier, sa faune et sa flore abondantes, ses traits culturels différents sont tous des éléments qui conviennent pour batir un produit touristique viable. Mais cela tarde a venir. Pourquoi? Sans doute parce que lá région n'a pas la cohésion culturelle des autres régions du Québec. Elle est plus exposée aux influences externes et aussi plus vulnérable.

Car pour "fabriquer et vendre" un produit touristique intéressant, il faut parfois y mettre son identité culturelle. Pour cela, il faut trouver ses origines et en être fiers pour être en mesure de les transmettre aux "étrangers". Or, ceci est difficile, si on ne revient pas ả la base, à ses racines en tant qu'individus. Tant dans l'Outaouais qu'à Ottawa, le nombre de gens de passage est très ćlevé. Les natifs de la région se font de plus en plus rare. La sous-région de la Petite-Nation est peut-être l'exception à la règle car elle possède tous les éléments pour fabriquer un produit touristique original et attrayant.

\section{Une authenticité discutable}

Les pratiques culturelles, les fétes, les ocuvres artisanales ou artistiques, des produits offerts aux touristes, perdent trop souvent leur authenticité pour devenir aseptises et commercialisés. Dans ces cas, la créativité et l'innovation sont remplacées par des considérations plus terre-à-terre, liées à la vente du produit, aux clientèles, au marketing, bref au profit.

Dans la Capitale, les événements qui célèbrent les saisons (Bal de Neige, Festival du Printemps et des Tulipes, Coloris automnal), les symboles (fêtes nationales) ou les parti- 
cularités culturelles (Festival Francoontarien) ne suffisent plus à insufler une vie, une ame, un esprit. Les gens ont besoin de plus de rencontres, d'échanges, de créativité dans un cadre moins formel et plus accessible. La formule idéale reste à inventer.

Le cas de Bal de Neige est intéressant: ill y a dix ans, c'était une grosse fête locale, aujourd'hui, I'événement a pris une proportion gigantesque. L'an prochain, on construira un énorme palais de glace, le plus gros au monde, dans l'espoir que nos amis canadiens et étrangers (surtout américains) le remarquent. Lorsqu'on compétionne dans les ligues majeures des grosses attractions, il faut y mettre le "paquet". Mais dans ce "package' que l'on offrira pour attirer et maintenir les touristes, où sont passées les habitudes de vivre l'hiver et les rites des hivers d'antan? Ceux-ci ont pris une saveur de cannelle et de sucre dans les queues de

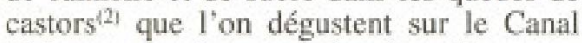
Rideau entre deux gorgées de café.

\section{Des visiteurs choyés}

On peut certes affirmer que les visiteurs de la Capitale sont de plus en plus choyés. On prépare des événements et des manifestations culturelles, on construit des musées et des promenades, tout cela pour qu'ils sejoument plus de trois jours. Les stratégies sont de plus en plus sophistiqués; on veut connaltre leurs gouts, leurs besoins, leurs attentes pour leur offrir un produit bien défini qui réponde à leurs criteres de consommateur.

Par ailleurs, les propriétaires d'hôtels et de restaurants voudraient que la Capitale diversifie ses sources d'attraction, comme le démontre l'étude de Lanventhol-Horwath. Mais ce genre d'attractions commerciales de type Disneyworld pose le difficile probleme de concilier la rentabilité financiêre et les préoccupations de la Capitale pour tous les Canadiens, telles qu'élaborées par la $\mathrm{CCN}^{(3)}$. Les rêves sont parfois confrontes at la dure réalité economique et politique du pays.

Dans l'Outaouais, la faiblesse vient surtout d'un manque de connaissances du visiteur potentiel qui souvent ne traverse pas la rivière. On voudrait mieux connaître ce qui le ferait franchir la rivière et l'inciter à y demeurer quelques jours. Des trois millions de visiteurs qui viennent dans la Capitale, à peine $10 \%$ se retrouvent dans 1'Outaouais. Les raisons sont variées: manque d'attractions, manque de services, peu d'informations, image touristique déficiente..

Souvent les commentaires font état qu'Outaouais ça sonne comme Ottawa (en anglais ça se prononce plus facilement). Il reste qu'une grosse part de la clientêle de la tégion est à Ottawa et qu'après leur visite du Parlement, des musées et du marché By, ils sont disponibles pour traverser. Nul doute que l'ouverture du musée canadien des Civilisations à Hull (800 000 visiteurs par anné) modifiera les flux et les stratégies touristiques de la région. Récemment, lors de la consultation tenue par la Commission de la Capitale nationale sur les Parcours d'honneur (dont une portion passe par la rue Laurier à Hull), un propriétaite a ouvert une boutique érotique en face du musee. La presse locale a fait grand étal de cette affaire, alléguant que ce n'est qu'à Hull qu'on trouve des faits de ce genre. Est-ce à dire que Nancy Reagan pourrait demander à son mari de regarder le musée plutôt que la boutique, lorsqu'ils emprunteront la route cerémoniale? Quoiqu'il en soit, ce fait cocasse fait ressortir l'écart dans la façon dont les communautés perçoivent les differrences culturelles et en font la promotion.

\section{De la feuille d'érable au castor}

$\mathrm{La}$ vente du produit touristique de la Capitale n'est pas toujours bien récussie. Les images et les symboles vendus demeurent toujours la feuille d'érable, la police monthe et récemment les queues de castors. Il n'y a pas eu de renouvellement du produit; souhaitons que l'ouverture des musées (Musée des Beaux-Arts et Musée de la Civilisation) entrâine un nouveau marketing de la Capitale.

Dans l'Outaouais, la question est differente, on se demande quoi vendre aux touristes. Certes les idees abondent:- l'artisanat et l'agneau de la Petite-Nation, les descentes en eau vive dans le Pontiac, le gibier des pourvoiries, la grande nature et I'experience française... Les produits locaux sont moins bien identifiés que dans d'autres régions mais tout aussi interessants. Les têtes de violon ${ }^{|4|}$ font partic de la cuisine locale de Montebello: elles sont délicieuses mais peu connues. Pourquoi esi-ce ainsi? Il semble exister une gêne collective à vouloir vendre les produits locaux, culinaires ou autres. Pourtant, il est reconnu qu'un produit varié et original a plus de chance d'attirer l'attention et qu'il fait partie de l'expérience du visiteur.

Ceci pose de nouveau une question fondamentale, faut-il avoir nécessairement un produit fort ou plusieurs produits variant selon les saisons et les modes? Dans cinq ans, les aquaparcs seront-ils toujours à la mode? Et les chevreuils, les outardes, les arbres serontils devenus des denrées rarissimes pour les urbains que nous sommes?

\section{Une image difficile à cerner}

Dans la Capitale, la population est partagée sur l'image qu'elle projette. À l'extérieur, nous savons que l'image n'est pas toujours positive. Ottawa signifie dans l'esprit des gens, siège du gouvernement et impôts à payer; Ottawa c'est aussi "les fat cats" (5) qui bénéficient des largesses du gouvernement et qui ne sont jamais contents; qui peut se permettre d'avoir des musees, des parcs, des promenades, des sentiers récreatifs payés à même les deniers publics.

Du côté de Hull, il faut surtout parler de l'image que d'autres lui imposent. Ville de plaisir après minuit, cette image est difficile à changer et lui restera accollée pendant des années. Mais on peut se demander si c"est acceptable... Pourquoi ne pas tirer avantage de cette réputation en la transformant graduellement? Il y a quelques années, l'Outaouais était reconnue pour la qualité de ses restaurants. Cet avantage s'est effrité peu à peu au profit d'Ottawa. Par ailleurs, les populations sont aussi partagees lorsqu'on parle de retombes touristiques. Tout le monde voulait que le train à vapeur de Wakefield survive, mais lorsque les residents ont su qu'il pourrait passer quatre fois par jour devant leur porte, la réaction fut nuancée, sinon négative. Je doute également que les résidents de la Petite-Nation (villégiateurs surtout) apprécient de voir deferler des milliers de visiteurs venus admirer les vestiges des Oueskarinis.

\section{Un mariage heureux!}

En somme, Capitale nationale, culture régionale et tourisme ça peut sembler un mariage heureux, mais il comporte un haut risque de divorce. Lorsqu'on vend une idée ou un produit touristique, on fait trop souvent abstraction des individus, qu'ils soient visiteurs ou visités. L'expérience vécue dans la région nous démontre que lorsqu"ill y a beaucoup de visiteurs, les visités se font rares pour les accueillir et fuient souvent vers leur chalet pres d'un lac. Par contre, dans l'Outaouais, les visités aimeraient bien avoir plus de visiteurs, mais il y en a définitivement trop peu qui $y$ viennent. $f$

\section{Notes explicatives:}

(1) Ottawa est juridiquoment la Capitale du Canada. La région de la Capitale nationale $\left(4662 \mathrm{~km}^{2}\right)$ s'etend du cotth ontarien et quebecois et eomprend 27 municipalit 2 s.

(2) Queues de castor: sorte de crepes faites de farine, de sucre et de cannelle vendues durant lo Ball de Neige.

(3) CCN: Commission de la Capitale Nationale.

(4) Partie de fougẻres comestibles.

(5) Traduction large: "riches di eraquer" ou "plein d'argent" 